to about 20000 village-level organisations. The N RSP and its sister organisations have agreed to include mental health among all their activities and about 20000 community activists will be trained each year through this initiative; this highlights the role of mental health in national development activities.

\section{Research and publications}

Lack of indigenous research has been a major hindrance to the rational planning and allocation of resources; however, over the past few years a number of research papers have been published. Major areas of research activity include: mental health policy research, epidemiology (M inhas et al, 2001), health systems, economic evaluation of models of mental health care delivery (Chisholm et $\mathrm{al}, 2000$ ), the development and validation of research instruments (Saeed et al, 2001), the evaluation of intersectoral linkages (Mubbashar et al, 2001) and clinical research.

\section{Legislation}

The government of Pakistan has repealed the Mental Health Act of 1912-26. The new mental health law, promulgated on 20 February 2001, embodies the modern concepts of mental illnesses, treatment, rehabilitation, and respect for civil and human rights. The first meeting of the Federal Mental $\mathrm{H}$ ealth Authority to develop an implementation mechanism for mental health ordinance 2001 was held on 29 December 2001. The ordinance provides for the prevention of mental illnesses, and the promotion of mental health through mental health literacy, the establishment of mental health services with stress on communitybased services and integration with primary health care, the protection of the human rights of people with mental illnesses, and the reduction of stigma and discrimination.

\section{References}

Chisholm, D., James, S., Sekar, K., et al (2000) Integration of mental health care into primary care: demonstration costoutcome study in India and Pakistan. British Journal of Psychiatry, 176, 581-588.

Husain, N ., Creed, F. \& Tomenson, B. (2000) Depression and social stress in Pakistan. Psychological Medicine, 30, 395-402.

Minhas, F. A., Farooq, S., Rahman, A., et al (2001) In-patient psychiatric morbidity in a tertiary care mental health facility: a study based on the case register. Journal of the College of Physicians and Surgeons of Pakistan, 11, 224-229.

Mohit, A., Saeed, K., Shahmohamadi, D., et al (1999) Mental health manpower development in Afghanistan: report of a training course for primary health care physicians. Eastern Mediterranean Health Journal, 5, 215-219.

Mubbashar, M. H. (1989) Promotion of mental health through school health programme. EM R H ealth Services Journal, 6, 14-19.

Mubbashar, S. S., Saeed, K. \& Gater, R. (2001) Reaching the unreached: evaluation of training of primary health care physicians. Journal of the College of Physicians and Surgeons of Pakistan, 11, 219-223.

Mumford, D. B., N azir, M., Jilani, F. U., et al (1996) Stress and psychiatric disorder in the $\mathrm{Hindu}$ Kush: a community survey of mountain villages in Chitral, Pakistan. British Journal of Psychiatry, 168, 299-307.

Mumford, D. B., Saeed, K., Ahmad, I., et al (1997) Stress and psychiatric morbidity in rural Punjab - a community survey. British Journal of Psychiatry, 170, 473-478.

Mumford, D. B., Minhas, F. A., Akhtar, I., et al (2000) Stress and psychiatric disorder in urban Rawalpindi: community survey. British Journal of Psychiatry, 177, 557-562.

Rahman, A., Mubbashar, M. H., Gater, R., et al (1998) Randomised trial of the impact of school health programme in rural Rawalpindi, Pakistan. Lancet, 352, 1022-1025.

Saeed, K., W irz, S., Gater, R., et al (1999) Detection of disabilities by school children: a pilot study in rural Pakistan. Tropical Doctor, 29, 151-155.

Saeed, K., Gater, R., Hussain, A. \& Mubbashar, M. (2000) The prevalence, classification and treatment of mental disorder among attenders of native faith healers in rural Pakistan. Social Psychiatry and Psychiatric Epidemiology, 35, 480-485.

Saeed, K., Mubbashar, S. S., Dogar, I., et al (2001) Comparison of self reporting questionnaire and Bradford somatic inventory as screening instruments for psychiatric morbidity in community settings in Pakistan. Journal of the College of Physicians and Surgeons of Pakistan, 11, 229-233.

Subcommittee on Mental Health and Substance Abuse (2003) Report of the Subcommittee on Mental Health and Substance Abuse. 9th Five Year Plan (1998-2003). Islamabad: Planning Commission, Government of Pakistan.
Lack of indigenous research has been a major hindrance to the rational planning and allocation of resources

\title{
Psychiatric country profile: Chile
}

\author{
Alfredo Pemjean
}

Ministerio de Salud, Unidad de Salud Mental, Maclver 541, Santiago, Chile, email apemjean@rdc.d

hile has approximately 600 psychiatrists for its 15 million people. Although in the capital city, Santiago, the provision (per capita) is twice as high as in the rest of the territory, it is possible to see over the past decade a progressive increase in the number of these specialists in the other main cities. There are no more than 50 child psychiatrists and several cities have no local resource in this sub-speciality.

\section{Training}

Ten schools of medicine offer medical undergraduate education. The seven-year curriculum includes courses on medical psychology, psychopathology and general psychiatry.

Physicians may become specialists in psychiatry through a three-year postgraduate programme of studies, provided by seven universities. All these residence programmes 
have similar coverage of neurology, in-patient wards and out-patient facilities and community mental health, as well as some adult and child psychiatry, the amount of which depends on the final speciality. Examinations vary across the residence programme: sometimes there are full examinations but, more frequently, there is formal approval after each one of the 6- or 12-month rotations.

Another way to obtain a speciality certificate is by undertaking formal clinical work, in a psychiatric clinical facility, that lasts at least five years; accreditation requires attendance at postgraduate courses and passing a formal examination, one week long, in a university centre.

Finally, a national independent organisation, CON ACEM, is the authority for specialist certification of physicians; the certificate is necessary for professional work and insurance purposes.

\section{Websites}

\section{M inistry of Health www.minsal.cl}

Sociedad Chilena De Neurología, Psiquiatría y Neurocirugía www.sonepsyn.cl

Sociedad Chilena de Salud Mental www. schilesaludmental.cl

\section{Corporacion}

Nacional Autonoma de Certificación de Especialidades Médicas www.conacem.cl

Fondo Nacional de Desarrollo Científico y Tecnológico www.fondecyt.cl

\section{Professional bodies and research}

Three main societies provide for scientific exchange among C hilean psychiatrists:

O The Society of N eurology, Psychiatry and N eurosurgery of C hile, founded in 1932, has a membership of 200 psychiatrists, in eight thematic working groups. It holds regular seminars, courses and a congress, and publishes two periodicals, the quarterly Revista Chilena de Neuropsiquiatría, and Folia Psiquiátrica, which appears three times a year

o The Chilean Society of Mental $\mathrm{H}$ ealth, founded in 1983, is a multiprofessional body; it has almost 300 members, more than 100 of whom are psychiatrists. Besides regular congresses and courses, it publishes one periodical, Revista Psiquiatría y Salud M ental.

O The C hilean Society of Psychiatry and $\mathrm{N}$ eurology of Childhood and Adolescence, which was fo unded in 1970.

Research by psychiatrists is largely into the epidemiology of mental disorders, quality of life associated with mental disorders and handicaps, evaluation of programmes and facilities, and, in the clinical arena, depression, suicide, personality disorders, post-traumatic stress disorder, drug and alcohol problems and adolescent mental health problems.

\section{Mental health services}

The public health sector, which provides medical services to $70 \%$ of the population, employed 168 general psychiatrists and 39 child psychiatrists in 2001. The numbers have been steadily increasing over the past 12 years.

The 28 territory general health services comprise a widely distributed primary health care network. This includes dispensaries and small, undifferentiated general hospitals, second-level speciality out-patient care, and large general hospitals with medical speciality wards, including psychiatry, in the main cities.

A new $N$ ational M ental Health Plan issued in 2000 resumed developments made in the previous 10 years, and marked the beginning of a new period which will see a transition from the traditional model of centralised care meeting the spontaneous demand of the population, to a network of facilities and programmes in which multiprofessional teams develop appropriate responses to mental health problems and preventive practice.

Some examples are given below:

- A national programme for the treatment of depression through primary health care, with the necessary second-level support, met the goal of treating 18000 women in 2001 and 24000 in 2002. For 2003, the goal is to offer protocol-guided treatment to 66000 women and men all over the country. 0 ne public health aim for 2010 is to reduce the prevalence of depression by $10 \%$ from the $7.5 \%$ rate measured in the 1990s.

- A national case register of patients with schizophrenia is supporting the prescription of clozapine and risperidone (in addition to the usual neuroleptics), through protocol-based distribution, to more than 3000 affected persons ( $83 \%$ of the estimated number of patients being treated within the public sector).

o Thirty-one day hospitals were opened in the year 2001, all over the country. This is a new type of psychiatric facility in Chile. Its goals are to diminish inpatient bed needs and the duration of hospitalisation; they provide more cost-effective care, nearer to patients' families. After a few months of operation, early evaluation has been promising.

- A growing number of treatment centres for drug and alcohol problems have been established since 2001. There are six treatment protocols in place: detoxification, dual pathology, ambulatory (first response, basic and intensive) and residential.

o A special form of consultation-liaison psychiatry service has been developed, called mental health consultation. Teams comprising at least one psychiatrist and one psychologist visit a particular primary care facility, once or twice a month, for a technical and planning meeting with the local team. The review of clinical problems of patients in the charge of both primary- and secondarylevel teams is at the core of the visit.

o Some major changes are also occurring within the inpatient wards, such as the differentiation of short- and medium-term hospitalisation, with a maximum of 60 and 189 days respectively. This has introduced a new dynamism in in-patient care.

o Finally, a gradual reduction in hospitalisation for chronic patients, together with the development of supervised community residence facilities, is in progress. Initial results have been good. H alf-w ay and more permanent homes for chronic patients, many of whom drop out of care from the existing four psychiatric hospitals, now have 700 residential places.

\section{Conclusion}

Chilean psychiatrists are coping with changes in the mental health care model. The process of reform in the health sector represents an opportunity and new challenges. 